\section{D Mobile Virtual \\ Reality Simulations and \\ Animations using \\ Common Modern Displays}

\section{Prof. Dr.-Ing. Andreas Christ \\ Prorektor der Hochschule Offenburg}

Badstr. 24

77652 Offenburg

Tel.: 0781 205-130

E-Mail: Christ@fh-offenburg.de

\section{8: Geboren}

Studium der Elektrotechnik an der Universität Karlsruhe,

Promotion an der Technischen Hochschule Darmstadt

über die numerische Berechnung dreidimensionaler

elektrodynamischer Felder,

Fünf Jahre tätig bei Siemens AG (u. a. Zentrale Forschung,

Öffentliche Telekommunikationsnetze, Mobilfunk).

Seit 1993: Professur an der Hochschule Offenburg

über Nachrichten- und Mikrowellentechnik

Seit 2001: Mitglied des Instituts für Angewandte Forschung (IAF)

der Hochschule Offenburg

Seit 2007: Prorektor der Hochschule Offenburg

Forschungsgebiete: Mobile Internet, Mobile Learning, VR-Visualisierung

\subsection{D Mobile Virtual Reality Simulations and Animations using Common Modern Displays}

Prof. Dr.-Ing. Andreas Christ

Prof. Dr. Dan Curticapean

Dr. Markus Feißt

\begin{abstract}
Die Autoren haben im Rahmen des Optik-Kongresses "Frontiers in Optics", der diesjährig in Rochester-New York stattfand, eine Lösung vorgestellt, die es ermöglicht, virtuelle Realität auf mobilen Endgeräten darzustellen.
\end{abstract}

Der Beitrag wurde von der Optical Society of America in Zusammenarbeit mit der American Physical Society als Highlight für Präsentationszwecke ausgewählt [*].

\section{Introduction and theoretical considerations}

Recent developments in information and communication technology, along with advanced displaying techniques and high computational performance open up new visualisation methods to both scientists and lecturers. Thus simulations of complex processes [1] can be computed and visualised in image sequences.

The particular idea in our approach is the outsourcing of computationally intensive calculations to servers which then send the results back to mobile users. In order to improve interpretations of the visualised results, users can view them in a 3D-perspective or stereoscopically, given the technical requirements. Today's technology even permits to view these visualisations on a mobile phone. An example for such a computationally intensive calculation originating from the theory of relativity is depicted in Figure 4.1-1.

\section{Computational architecture}

$3 \mathrm{D}$ virtual reality (VR) can provide a realistic presentation of information to the user. With the help of description languages for virtual reality powerful means are available. Nowadays the processing power of mobile phones, smart phones and personal digital assistants is increasing, as well as the transmission bandwidth [2]. Nevertheless there is still need to reduce the content and processing it.
The system which optimises and sends the VR data to the connected mobile phone is called VRML proxy system ( $\mathrm{Fi}$ gure 4.1-2). In order to visualise the VR data on external devices such as a two video projector system, the connection between the mobile phone and the display system or a head mounted device could be done over a wireless Bluetooth connection, thus the user's mobility is preserved. In order to generate a stereoscopic view on the mobile device screen, the following three possibilities are usable [3]:

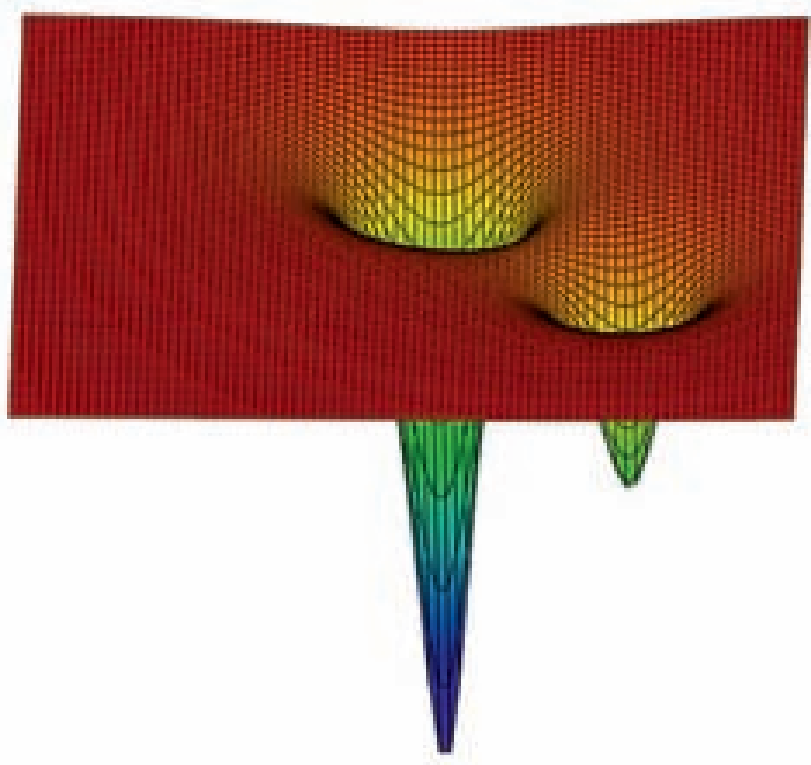

Fig. 4.1-1: Performed simulation (Fig. from conference poster) 


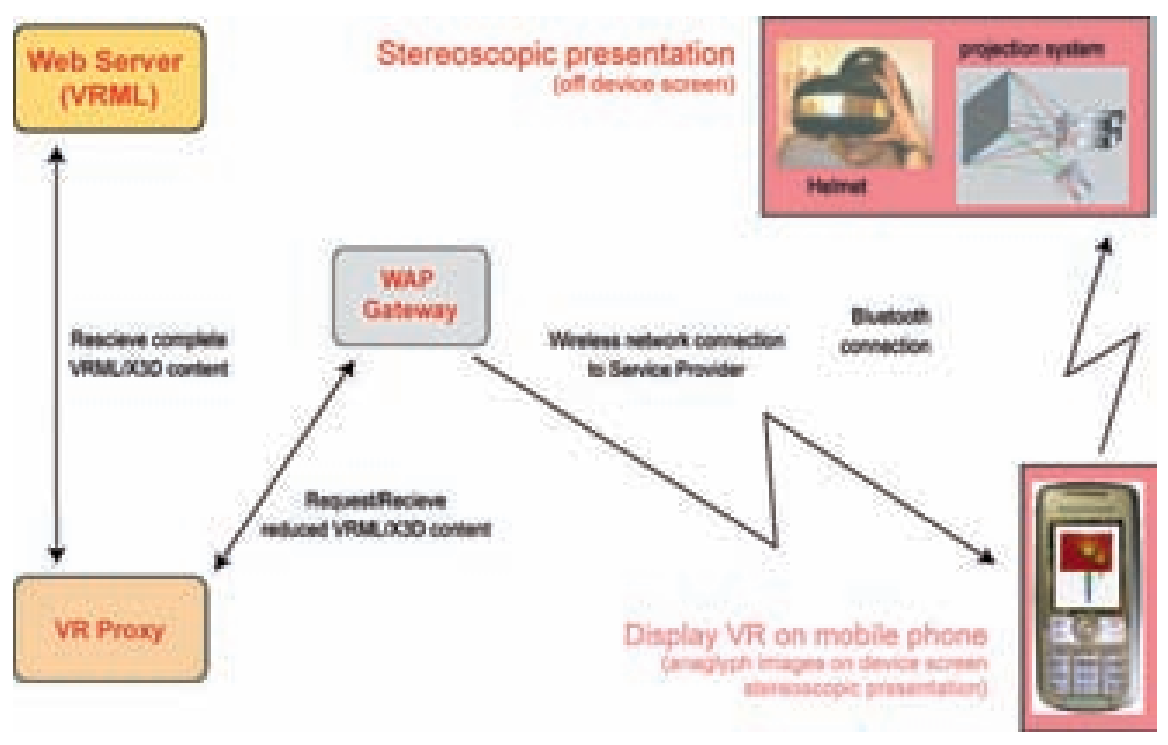

Fig. 4.1-2: Computational architecture [4]

- Build in three-dimensional screen (with ready three-dimensional screen);

- Lenticular lenses (sheet of parallel cylindrical lenses using the principle of parallax barrier); the mode of opera- tion is similar the build in threedimensional screen;

- Anaglyph images (colour filtered combination of the image for the left and right eye) (Figure 4.1-3).

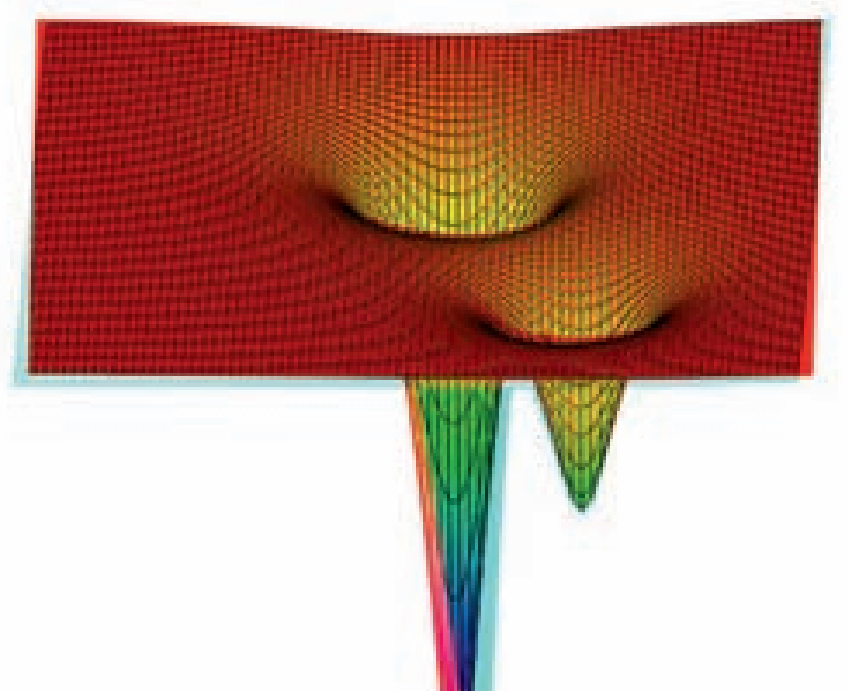

Fig. 4.1-3: Anaglyph image simulation

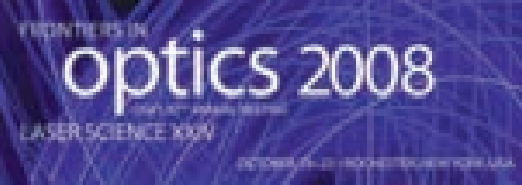

WASHINGTON, Oct. 8 -- Frontiers in Optics 2008 (FiO), the 92nd Annual Meeting of the Optical Society (OSA), will be held from Oct. 19-23 at the Riverside Convention Center in Rochester, N.Y. FiO 2008 will take place alongside Laser Science XXIV, the annual meeting of the American Physical Society's Division of Laser Science.

\section{FiO RESEARCH HIGHLIGHTS}

Reality to Go: 3-D Virtual Reality on Mobile Devices

A Potential New Tool for Brain Surgeons

New Optics for Improved Solar Power Generators

Using Algae to Convert Sunlight into Biofuel

Highest Power Tabletop Laser Ever Built

\section{References}

[1] Curticapean Dan, Neculae Adrian: "Temperature measurement using optical fiber with applications to automobiles considering a high accurate numerical solution for the conductive heat transport in a circular cylinder" - Proceedings of SPIE - Volume 7003 Optical Sensors 2008, 70032K, 2008 ISBN: 9780819472014

[2] Donelan Jenny: "Pocket Pictures" Computer Graphics World Issue Date: Volume: 25 Issue: 10 (October 2002)

[3] Hollman Nick, "3D Display Systems: University Research and Education in Europe", invited presentation to the first European meeting of the global 3D Consortium, June 2003, Luxembourg

[4] Feißt, M.: Etude de Protocole et Réalisation d'un Système de Réalité Augmentée Mobile. Promotion 2006. Université Louis Pasteur, Stras bourg 